\title{
Do physicians have a duty to share their views on social media?
}

\author{
C Cite as: CMAJ 2018 March 12;190:E302-3. doi: 10.1503/cmaj.109-5571
}

Posted on cmajnews.com on Feb. 20, 2018.

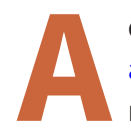
doctor posts a series of tweets about racism in emergency rooms. A doctor posts a tweet of himself "taking a knee." A doctor posts a string of tweets about an irritating cell phone conversation he is forced to overhear in a crowded train.

All of the above are recent examples of social media interactions by physicians. Sometimes it's easy - but just as often it's hard - to know when a line is being crossed. What is okay? What is not?

"I think doctors should be encouraged to use social media platforms to discuss issues that are important to them, and about which they are knowledgeable," said Dr. David Juurlink, an internal medicine doctor and pharmacologist at Sunnybrook Health Sciences Centre in Toronto.

In fact, he argues that it is incumbent on doctors, as learned individuals, to share their perspectives - "ideally supported by facts and reason and logic." This goes for personal experiences too, he says, noting that he is a follower of the emergency room doctor who posted about racism, and feels she moved an important public discussion forward in a constructive way.

Dr. Eric Benchimol, a pediatric gastroenterologist at the Children's Hospital of Eastern Ontario, and a regular user of social media, goes further. Despite the dangers of using social media, he says, there's even more danger in not using it. "If we don't help shape the discussion," he says, "it will be shaped without us."

As an example, he points to the circus surrounding "liberation therapy," in which an Italian doctor claimed that multiple sclerosis was caused by poor drainage of blood from the brain and that improving that flow with a procedure like they work or what they do. Even when they have reason to think the platform they are using is private, they should behave as though it isn't, he says. "You should never say anything on social media that you wouldn't want on the front page of the local newspaper."

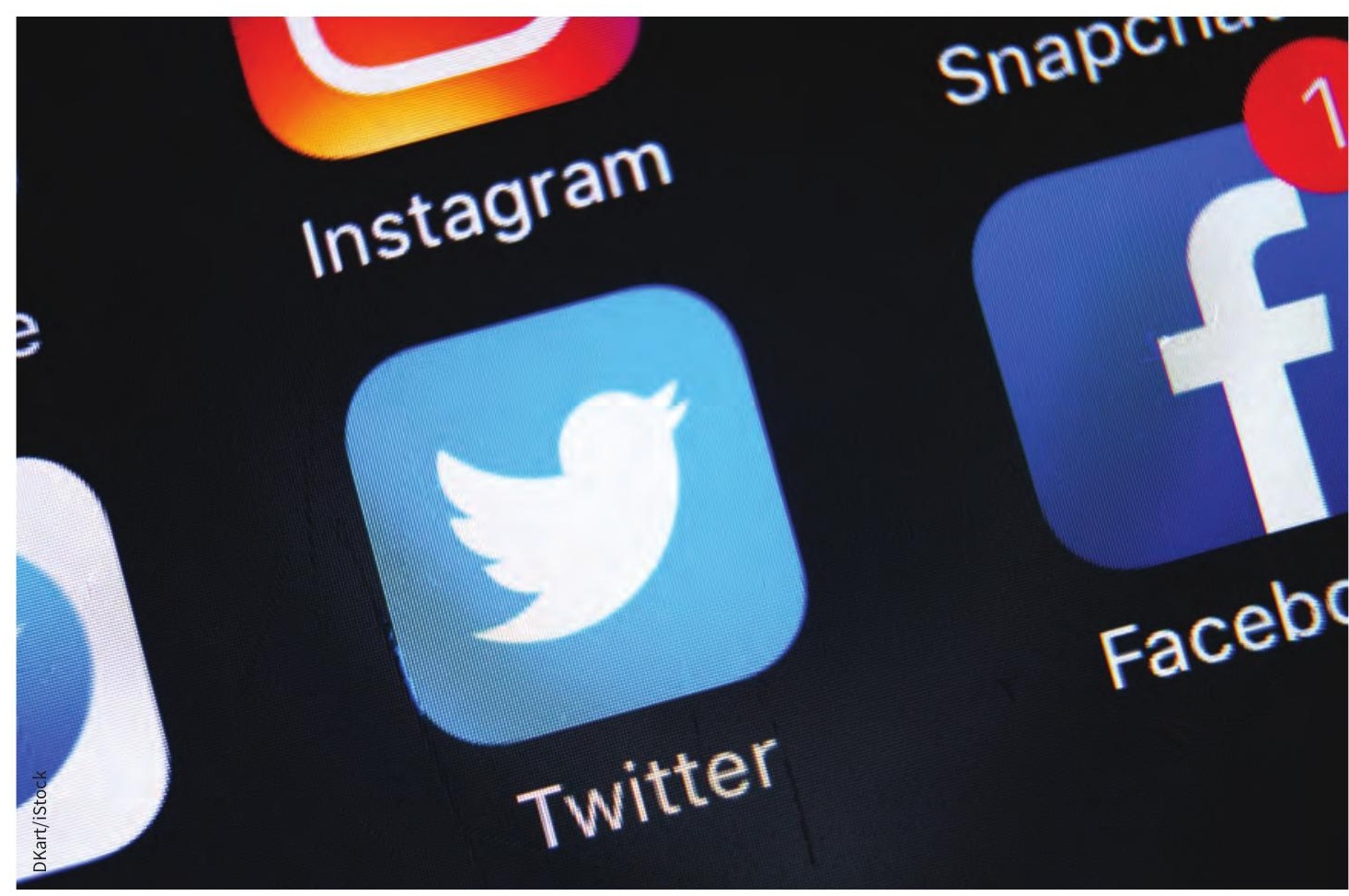

Some doctors feel it's important to help shape discussions on social media about important health topics. angioplasty could dramatically improve symptoms. A recent editorial in Scientific American makes a similar case, suggesting that academics and scientists should be encouraged to contribute to public debates about important issues.

Doctors do have to be mindful that, to a certain extent, they are public figures, says Benchimol. As such they should never try to be anonymous, or obscure where
Medical bodies have tried to bring some clarity. In its 2011 policy, the Canadian Medical Association reminded doctors that on social media they are "governed by the same ethical and professional standards that have always applied." The policy underscores that patient confidentiality is still key; doctors need to bear in mind that anything they share can eventually become public; nothing is really anonymous; and 
doctors can't control what happens to what they post after they release it into the ether.

In practice, however, navigating between the professional, the unprofessional and the personal can be tricky. Dr. Esther Choo, an Asian-American emergency physician in Portland, Oregon, who has 15 years experience and was trained at Yale, tweeted last August about how white patients sometimes prefer to be treated by interns, or not be treated at all, than be treated by someone of her race. Her thread was retweeted thousands of times.

In September, general surgery resident Dr. Eugene Gu tweeted, "I'm an
Asian-American doctor and today I \#TakeTheKnee to fight white supremacy." It was also retweeted thousands of times. But the tweet garnered censure from his own institution, Vanderbilt University Medical Center, according to Gu. As discipline for this and other tweets, which include political comments and a complaint about a colleague, Gu says he was forced to take two weeks paid leave in November, and has been put on probation until March.

Many medical schools do not encourage young doctors, researchers or faculty to have a social media presence. Part of the reason may be that doctors often perceive impropriety differently than patients, supervisors and regulatory bodies. One study, for instance, asked emergency doctors to rate how likely it was that a hypothetical social media behaviour would be investigated and disciplined by regulators. The researchers compared doctors' answers to those of state medical board directors. The two groups had a difference of opinion on the hypothetical scenarios dealing with disrespectful speech and including alcohol in an image. Doctors were more likely to rate these as fine, whereas boards were more likely to say they'd investigate and take action.

Alison Motluk, Toronto, Ont. 